\title{
Analisis Kualitas Air Permukaan Rawa Gambut Rasau Bervegetasi Mangrove Di Desa Rantau Panjang Kabupaten Muaro Jambi
}

\author{
Guntar Marolop $S^{1}$, Peppy Herawati ${ }^{2}$ \\ ${ }^{1,2}$ Fakultas Teknik Universitas Batanghari Jambi \\ Correspondence email: saragihguntar@gmail.com
}

\begin{abstract}
Abstrak. Tanah gambut adalah jenis tanah yang terbentuk dari akumulasi sisa tumbuhan yang mengalami proses pembusukan oleh sebabnya tanah gambut mengandung zat organik tinggi dan besifat asam. Tanah gambut akan mempengaruhi parameter suatu ekosistem perairan sekitarnya, misalnya seperti ekosistem rawa gambut Rasau di desa Rantau Panjang. Parameter air rawa gambut dipengaruhi oleh zat-zat yang tersimpan dalam gambut seperti memiliki $\mathrm{pH}$ yang rendah, kandungan logam berat yang tinggi, serta memiliki nilai TSS, TDS, BOD dan COD yang tinggi. Parameter air rawa gambut yang bervegetasi mangrove lebih baik bila dibandingkan dengan rawa gambut yang tidak bervegatasi mangrove. Hal ini dapat diketahui bila parameter air rawa gambut di uji laboratorium. Parameter yang diuji adalah parameter yang terpengaruh oleh kandungan gambut yakni temperatur, TDS, DHL, Warna, dan kekeruhan serta $\mathrm{pH}, \mathrm{BOD}, \mathrm{COD}, \mathrm{Mn}$, dan besi (Fe). Parameter fisika air yakni temperatur, TDS, DHL, Warna, dan kekeruhan lebih rendah di rawa gambut Rasau bervegetasi mangrove dibanding dengan yang tidak bervegetasi. Parameter kimia rawa gambut Rasau bervegetasi mangrove kerapatan tinggi seperti pH-nya lebih tinggi, serta BOD, COD, dan besi (Fe) lebih rendah bila dibandingkan dengan rawa gambut tidak bervegetasi mangrove. Namun parameter fisika dan kimia dari rawa gambut yang bervegetasi maupun yang tidak bervegetasi mangrove masih di atas baku mutu standar PPRI No. 82 Tahun 2001.
\end{abstract}

Kata kunci: Rawa gambut; mangrove; parameter air permukaan

\begin{abstract}
Peat soil is a type of soil that is formed from the accumulation of plant debris which undergoes a decomposition process. This is why peat soil contains high organic matter and is acidic. Peat soils will affect the parameters of a surrounding aquatic ecosystem, such as the Rasau peat swamp ecosystem in the village of Rantau Panjang. Peat swamp water parameters are influenced by substances stored in the peat such as having a low pH, high heavy metal content, and having high TSS, TDS, BOD and COD values. The water parameter of peat swamp with mangrove vegetation is better than that of peat swamp that does not have mangrove vegetation. This can be seen if the peat swamp water parameters are laboratory tested. The physical parameters of water, namely temperature, TDS, DHL, color, and turbidity were lower in the Rasau peat swamp with mangrove vegetation compared to the non-vegetated ones. The chemical parameters of the Rasau peat swamp with high density mangrove vegetation such as higher $\mathrm{pH}$, and lower $\mathrm{BOD}, \mathrm{COD}$, and iron $(\mathrm{Fe})$ when compared to peat swamps without mangrove vegetation. However, the physical and chemical parameters of vegetated and non-vegetated peat swamps are still above the PPRI No. 82 of 2001.
\end{abstract}

Keywords: Peat swamps; mangroves; surface water parameters

\section{PENDAHULUAN}

Di rawa gambut terdapat vegetasi air yang endemik, salah satu vegetasi endemik yaitu vegetasi mangrove. Dengan adanya vegetasi mangrove, kualitas air permukaan rawa gambut akan berubah bila dibandingkan dengan rawa gambut yang tidak bervegetasi mangrove. Mangrove mampu menyerap beberapa zat yang bersumber dari gambut sehingga besaran parameter air permukaannya akan mendekati parameter air sungai pada umumnya. Dari sisi lain, mangrove banyak dimanfaatkan sehingga vegetasi mangrove semakin sedikit.

Demikian halnya di rawa gambut Rasau di desa Rantau Panjang Kabupaten Muaro Jambi. Rawa gambut Rasau ditumbuhi vegetasi mangrove yang kerapatannya tinggi. Namun untuk memenuhi kepentingan manusia, lahan ekosistem mangrove banyak dialihfungsikan sehingga kerapatan vegetasi mangrove semakin menurun. Sementara, salah satu fungsi ekologi vegetasi mangrove adalah menyerap beberapa zat yang bersumber dari tanah gambut. Yulia Morsa Said, Yudi Achnaopa, dkk, 2019, menyatakan bahwa di air gambut daerah lahan basah Provinsi Jambi khususnya di daerah Tungkal Ilir, Kabupaten Tanjung Jabung Barat memiliki parameter air berwarna cokelat kehitaman, kandungan logam berat tinggi disebabkan oleh kontaminasi gambut, DHL yang tinggi, serta memiliki nilai $\mathrm{pH}$ yang sangat rendah.

Dari penjelasan di atas, maka yang dikaji dalam penelitian ini adalah bagaimana parameter air rawa gambut Rasau di lokasi yang bervegetasi mangrove kerapatan tinggi serta di lokasi rawa gambut yang tidak bervegetasi mangrove.

Manfaat diketahuinya parameter air rawa gambut Rasau yang bervegetasi mangrove dan parameter air rawa gambut yang tidak bervegetasi mangrove adalah agar para pihak dan masyarakat setempat semakin mengerti manfaat vegetasi mangrove di rawa gambut. 


\section{METODE}

Penelitian ini merupakan penelitian deskriptif, yaitu penelitian dengan pendekatan kuantitatif untuk menggambarkan perubahan parameter air rawa gambut Rasau antara yang bervegetasi dengan yang tanpa vegetasi mangrove.

Air rawa gambut ini mengalir dari danau Rasau sekitar 1 kilo meter di hulu lokasi sampel yang bermuara ke sungai Batang Hari. Lokasi sampel ada 2 lokasi, 1 lokasi di rawa gambut yang bervegetasi mangrove dan 1 lokasi di rawa gambut yang tidak bervegetasi mangrove. Pengambilan sampel air permukaan rawa gambut Rasau mengikuti "metode pengambilan contoh uji air permukaan" seperti pada SNI 6989.57:2008. Acuan yang digunakan untuk menganalisis parameter fisika-kimia air permukaan rawa gambut Rasau adalah PPRI Nomor 82 Tahun 2001 Tentang Pengelolaan Kualitas Air Dan Pengendalian Pencemaran Air (kelas II). Parameter air permukaan yang dianalisis adalah suhu, TSS, TDS, DHL, warna, kekeruhan, pH, BOD, COD, Fe, dan Mn.

\section{HASIL DAN PEMBAHASAN}

Adapun hasil uji parameter air permukaan rawa gambut Rasau yang dilakukan di laboratorium adalah seperti pada Tabel 1.

Tabel 1. Parameter air permukaan rawa gambut Rasau

\begin{tabular}{|c|c|c|c|c|c|}
\hline \multirow{2}{*}{ No } & \multirow{2}{*}{$\begin{array}{c}\text { Parameter } \\
\text { Parameters }\end{array}$} & \multirow{2}{*}{$\begin{array}{c}\text { Satuan } \\
\text { Unit }\end{array}$} & \multicolumn{2}{|c|}{ Hasil Uji } & \multirow{2}{*}{$\begin{array}{c}\text { Baku Mutu } \\
\text { Standart }\end{array}$} \\
\hline & & & $\mathrm{AP}_{1}$ & $\mathrm{AP}_{2}$ & \\
\hline I & Fisika & & & & \\
\hline 01 & Temperatur & $\left({ }^{\circ} \mathrm{C}\right)$ & 28 & 26 & Deviasi \pm 3 \\
\hline 02 & TSS & $(\mathrm{mg} / \mathrm{L})$ & 5 & 5 & 50 \\
\hline 03 & TDS (mg/L) & $(\mathrm{mg} / \mathrm{L})$ & 20 & 19 & 1.000 \\
\hline 04 & DHL & $(\mu \mathrm{s} / \mathrm{cm})$ & 36,8 & 36,5 & - \\
\hline 05 & Warna & (Pt.Co) & 10 & 9 & - \\
\hline 06 & Kekeruhan & (NTU) & 0,23 & 0,01 & - \\
\hline II & Kimia & & & & \\
\hline 07 & $\mathrm{pH}$ & $(\mathrm{mg} / \mathrm{L})$ & 4,3 & 5,5 & $6-9$ \\
\hline 08 & BOD & $(\mathrm{mg} / \mathrm{L})$ & 12 & 1,6 & 3 \\
\hline 09 & COD & $(\mathrm{mg} / \mathrm{L})$ & 88 & 86 & 25 \\
\hline 10 & Besi $(\mathrm{Fe})$ & $(\mathrm{mg} / \mathrm{L})$ & 0,70 & 0,59 & $(-)$ \\
\hline 11 & Mangan (Mn) & $(\mathrm{mg} / \mathrm{L})$ & $<0,01$ & $<0,01$ & $(-)$ \\
\hline
\end{tabular}

Sumber: Data primer, 2020

Ket:

$\mathrm{AP}_{1} \quad$ : Lokasi sampel di rawa gambut tanpa vegetasi mangrove

$\mathrm{AP}_{2} \quad$ : Lokasi sampel di rawa gambut bervegatasi mangrove

Diperoleh hasil bahwa temperatur di $\mathrm{AP}_{1}\left(28^{\circ} \mathrm{C}\right)$ lebih tinggi dengan di $\mathrm{AP}_{2}\left(26^{\circ} \mathrm{C}\right)$. Perbedaan ini dipengaruhi oleh besarnya penyinaran mata hari di $\mathrm{AP}_{1}$ yang telah terbuka karena tidak adanya vegetasi mangrove. Menigkatnya temperatur air permukaan dapat menyebabkan metabolisma dan respirasi air meningkat sehingga akan menambah kekeruhan dan memperbesar parameter warna air rawa gambut yang semakin cokelat.

Total Suspended Solids (TSS) adalah padatan yang menyebabkan kekeruhan air, tidak terlarut dan tidak dapat mengendap langsung. Padatan ini terdiri dari partikel ukuran kecil dan beratnya lebih kecil dari sedimen, misalnya bahan-bahan organik tertentu. TSS memberikan kontribusi untuk kekeruhan.

Total Disolved Solids (TDS) merupakan padatan yang terlarut dalam air berupa zat organic ataupun anorganik. Penyebab terbentuknya TDS adalah adanya bahan-bahan organic berupa ion-ion yang dijumpai di perairan yang bias bersumber dari limbah domestik seperti sabun dan deterjen. Pada rawa gambut, TDS dapat disebabkan oleh senyawa organik. TDS berasal dari bahan organik gambut yang terdekomposisi oleh air dan dari aktivitas nelayan yang menggunakan deterjen sebagai pembersih. Dari Tabel 2 terlihat bahwa TDS di rawa gambut tidak bervegetasi mangrove $\left(\mathrm{AP}_{1}=20\right)$ lebih besar dari lokasi bervegetasi mangrove $\left(\mathrm{AP}_{2}=19\right)$, namun masih memenuhi baku standar sesuai PPRI Nomor 82 Tahun 2001 kelas II. Perbedaan nilai TDS ini menunjukkan bahwa mangrove di $\mathrm{AP}_{2}$ berfungsi menyerap TDS.

DHL disebut juga konduktivitas air. Air tercemar memiliki nilai konduktivitas tinggi. Dengan demikian nilai konduktivitas air rawa gambut juga tinggi. Nilai konduktivits yang tinggi menyebabkan air mudah menghantarkan listrik dan mengindikasikan adanya kandungan asam yang tinggi. Kandungan asam yang tinggi pada air gambut akan menyebabkan air memiliki $\mathrm{pH}$ rendah sehingga tidak layak untuk dikonsumsi. Dari Tabel 1 terlihat bahwa DHL di rawa gambut tidak bervegetasi mangrove $\left(\mathrm{AP}_{1}=36,8\right)$ lebih besar dari lokasi bervegetasi mangrove $\left(\mathrm{AP}_{2}=36,5\right)$ dan 
Guntar Marolop S dan Peppy Herawati, Analisis Kualitas Air Permukaan Rawa Gambut Rasau Bervegetasi Mangrove Di Desa Rantau Panjang Kabupaten Muaro Jambi

tidak memenuhi baku mutu standar sesuai PPRI Nomor 82 Tahun 2001 kelas II. Perbedaan nilai DHL menunjukkan bahwa mangrove di $\mathrm{AP}_{2}$ berfungsi menyerap TDS.

Air gambut memiliki warna cokelat hingga hitam pekat yang disebabkan oleh material organik tumbuhan yang berubah menjadi gambut. Warna air gambut yang cokelat hingga hitam diakibatkan dari tingginya kandungan zat organik (bahan humus) terlarut dalam bentuk asam humus. Asam humus berasal dari dekomposisi bahan biomassa seperti daun, pohon, atau kayu dengan berbagai tingkat dekomposisi di gambut. Selain warna, air gambut juga memiliki kekeruhan cukup tinggi, nilai $\mathrm{pH}$ yang rendah $(<7)$ dan

kadar BOD serta COD yang tinggi. $\mathrm{pH}$ air gambut yang rendah disebabkan oleh asam fulvat, humin dan asam humat. $\mathrm{pH}$ air gambut yang rendah menyebabkan air terasa asam yang dapat menimbulkan kerusakan gigi dan sakit perut pada manusia.

Kadar BOD dan COD yang tinggi diakibatkan oleh biomassa yang terdekomposisi dan berassosiasi dalam gambut. Kadar COD disamping terpengaruh oleh dekomposisi biomassa dari gambut juga dipengaruhi oleh limbah rumah tangga seperti deterjen dan bahan kimia yang digunakan pada aktivitas rumah tangga. Besarnya nilai COD di air permukaan rawa gambut Rasau dimungkinkan dipengaruhi oleh aktivitas masyarakat di sekitar lokasi sampel dan di danau Rasau di hulu lokasi sampel. Aktivitas masyarakat tersebut adalah menangkap ikan tembakang dan ikan endemic lainnya. Menurut masyarakat setempat, jumlah nelayan local yang menangkap ikan di danau dan di rawa gambut Rasau sekitar 100 orang per hari. Ikan tembakang hasil tangkapan nelayan lokal mencapai 1-1,5 ton per hari. Setelah melakukan aktivitasnya, nelayan menggunakan deterjen dalam membersihkan sarana-prasarana yang dipegunakannya.

Logam berat besi $(\mathrm{Fe})$ dan mangan $(\mathrm{Mn})$ merupakan unsur logam berat yang signifikan terdapat pada air yang terpengaruh gambut. Kandungan logam berat yang tinggi pada air gambut akan menyebabkan berbagai permasalahan kualitas air permukaan. Kandungan Fe dan Mn di dua lokasi memenuhi PPRI Nomor 82 Tahun 2001 kelas II. Konsentrasi Fe lebih besar di lokasi $\mathrm{AP}_{1}(0,70)$ dibanding dengan di $\mathrm{AP}_{2}(0,59)$ karena terserap oleh vegetasi mangrove.

Kadar Mn di kedua lokasi besarnya sama yaitu $<0,01 \mathrm{mg} / \mathrm{liter}$. Perbedaan besaran kadar Mn di kedua lokasi tidak terdeteksi, hal ini disebabkan oleh limit deteksi instrument atomic absorption spectrophotometry yang digunakan. Secara keseluruhan kaberadaan gambut di lokasi penelitian, menyebabkan parameter air rawa gambut Rasau yaitu DHL, warna, kekeruhan, pH, BOD, COD, dan besi (Fe) di atas baku mutu standart dari PPRI Nomor 82 Tahun 2001 kelas II.

Keberadaan ekosistem gambut di lahan basah seperti di dasar rawa, akan mempengaruhi kualitas air yang terdapat di rawa tersebut. Beberapa unsur yang terlepas dari ekosistem gambut dan menyatu dengan air adalah unsur mangan (Mn) dan besi (Fe) serta airnya berwarna cokelat bersifat asam. Walaupun keberadaan unsur Fe dan Mn tinggi di rawa gambut serta airnya berwarna cokelat bersifat asam $(\mathrm{pH}<7)$, namun tidak dikatakan air rawa gambut tercemar karena itulah karakteristik alaminya. Dengan tingginya kadar parameter unsur gambut di rawa gambut menjadikan rawa gambut sebagai habitat biota dan vegetasi endemik tertentu. Salah satu biota endemik di rawa gambut Rasau adalah terdapatnya ikan tembakang dalam jumlah melimpah.

Vegetasi endemiknya adalah terdapatnya mangrove jenis Avicennia Marina dan Rhizophora spp dengan kerapatan tinggi. Untuk mempertahankan kelestarian rawa gambut Rasau sesuai dengan peruntukannya, sebaiknya keberadaan ekosistem mangrove tidak dialihfungsikan. Selanjutnya, bila air rawa gambut dimanfaatkan untuk air baku untuk diolah menjadi air bersih maka peranan vegetasi mangrove untuk menurunkan beberapa parameter air permukaan sangat penting. Kualitas air permukaan rawa gambut harus memenuhi baku mutu standar air baku untuk air bersih. Air rawa gambut Rasau bermuara ke sungai Batang Hari. Air sungai Batang Hari dimanfaatkan oleh masyarakat untuk mandi, cuci dan kebutuhan lainnya. Oleh karenanya maka pengalihfungsian ekosistem mangrove di rawa gambut Rasau harus dihindari. Alasan ini didasarkan pada perbedaan parameter air permukaan rawa gambut yang bervegetasi mangrove dengan yang tidak bervegetasi mangrove. Semua parameter air permukaan yang diuji dalam Table 2, lebih baik kualitas air dari lokasi $\mathrm{AP}_{2}$. Bila dibandingkan dengan kualitas air di $\mathrm{AP}_{1}$ yang mengacu ke PPRI Nomor 82 Tahun 2001 kelas II.

\section{SIMPULAN}

Besar parameter fisika air permukaan rawa gambut Rasau tidak bervegetasi mangrove $\left(\mathrm{AP}_{1}\right)$ adalah temperatur $=28^{\circ} \mathrm{C}, \mathrm{TDS}=20 \mathrm{mg} / \mathrm{L}, \mathrm{DHL}=36,8 \mu \mathrm{s} / \mathrm{cm}$, Warna $=10 \mathrm{Pt} . \mathrm{Co}$, dan kekeruhan $=0,23 \mathrm{NTU}$. Besar parameter fisika air permukaan rawa gambut Rasau bervegetasi mangrove kerapatan tinggi $\left(\mathrm{AP}_{2}\right)$ adalah temperatur $=26^{\circ} \mathrm{C}$, TDS $=19$ $\mathrm{mg} / \mathrm{L}, \mathrm{DHL}=36,5 \mu \mathrm{s} / \mathrm{cm}$, Warna $=9$ Pt.Co, dan kekeruhan $=0,01 \mathrm{NTU}$.

Parameter fisika air permukaan rawa gambut Rasau $\mathrm{AP}_{2}$ baik/rendah dibandingkan dengan air gambut pada $\mathrm{AP}_{1}$.

Besar parameter kimia air permukaan rawa gambut Rasau tidak bervegetasi mangrove $\left(\mathrm{AP}_{1}\right)$ adalah $\mathrm{pH}=4,3$, $\mathrm{BOD}=12 \mathrm{mg} / \mathrm{L}, \mathrm{COD}=88 \mathrm{mg} / \mathrm{L}$, dan besi $(\mathrm{Fe})=0,70 \mathrm{mg} / \mathrm{L}$. Parameter kimia air permukaan rawa gambut Rasau bervegetasi mangrove kerapatan tinggi $\left(\mathrm{AP}_{2}\right)$ adalah $\mathrm{pH}=54,3, \mathrm{BOD}=12 \mathrm{mg} / \mathrm{L}, \mathrm{COD}=88 \mathrm{mg} / \mathrm{L}$, dan besi $(\mathrm{Fe})=$ 
Guntar Marolop S dan Peppy Herawati, Analisis Kualitas Air Permukaan Rawa Gambut Rasau Bervegetasi Mangrove Di Desa Rantau Panjang Kabupaten Muaro Jambi

0,70 mg/L. Parameter kimia air permukaan rawa gambut Rasau $\mathrm{AP}_{2}$ lebih baik/rendah dibandingkan dengan air gambut pada $\mathrm{AP}_{1}$.

\section{DAFTAR PUSTAKA}

Agus F.dan G.M.Subiksa, 2008, Lahan Gambut: Potensi Untuk Pertanian Dan Aspek Lingkungan, Balai Penelitian dan World Agroforestry Center, Bogor.

Anonim, 2001, PPRI Nomor 82 Tahun 2001 Tentang Pengelolaan Kualitas Air Dan Pengendalian Pencemaran Air, Jakarta.

Naswir, M., Arita, S., Hartati, W., dkk., 2019. Activated Bentonite : Low Cost Adsorbent to Reduce Phosphor in Waste Palm Oil. International Journal of Chemistry, 11 (2).

Pramudji, 2018, Mangrove Di Indonesia 2018, ISSN : 978-602-6504-08-1, LIPI, Jakarta.

Yulia Morsa Said, Yudi Achnopa, dkk, 2019, Karakteristik Fisik Dan Kimia Air Gambut Kabupaten Tanjung Jabung Barat, Provinsi Jambi, Jurnal Sains dan Teknologi Lingkungan Vol.2, Juni 2019, Universitas Jambi, Jambi. 